\title{
VIRUS PNEUMONIA
}

\author{
By Horace Joules, M.D., F.R.C.P. \\ Central Middlesex Hospital
}

The importance of virus pneumonia is becoming increasingly realized because of the effective treatment of bacterial infections. In the best hands bacterial pneumonia now has a mortality of less than 5 per cent., except at the extremes of age and in those gravely ill from other diseases. Its incidence, too, is falling rapidly, while the duration of the illness is counted in days as against weeks or months a decade ago. In contrast the incidence of virus infections of the upper respiratory tract remains almost untouched by modern therapy. In America disease resulting from this cause accounts for 32 per cent. of all medical visits to the home (Reimann, I946). As is well known the severer infections frequently result in pneumonic consolidations, but difficulty arises in differential diagnosis from two main causes:--

I. Virus isolation and culture are extremely difficult and time consuming. Not all the types are known yet.

2. The association between virus and bacteria is so close that in many diseases it is as yet impossible to assign distinct roles to each. Dogmatism is thus impossible and this classification is purely tentative.

'Pneumonia' is used to denote a condition in which consoidation of the lung can be demonstrated, clinically or radiologically, and which is due to inflammatory alveolar exudate. It is desirable, when the term is used, that it should always be qualified by a causative organism, or other factor. Without such diagnostic clarity rational therapy cannot be given, nor can there be any valid comparison between published results.

\section{Suggested Classification}

I. Influenzal pneumonia.

2. Primary atypical pneumonia.

3. Pneumonia due to unknown virus.

4. Psittacosis or ornithosis pneumonia.

5. Known virus infections occasionally causing pneumonia :--

(a) Measles.

(b) Varicella.

(c) Variola.

(d) Infectious mononucleosis.

(e) Lymphocytic choriomeningitis.

(f) Lymphogranuloma venerum.

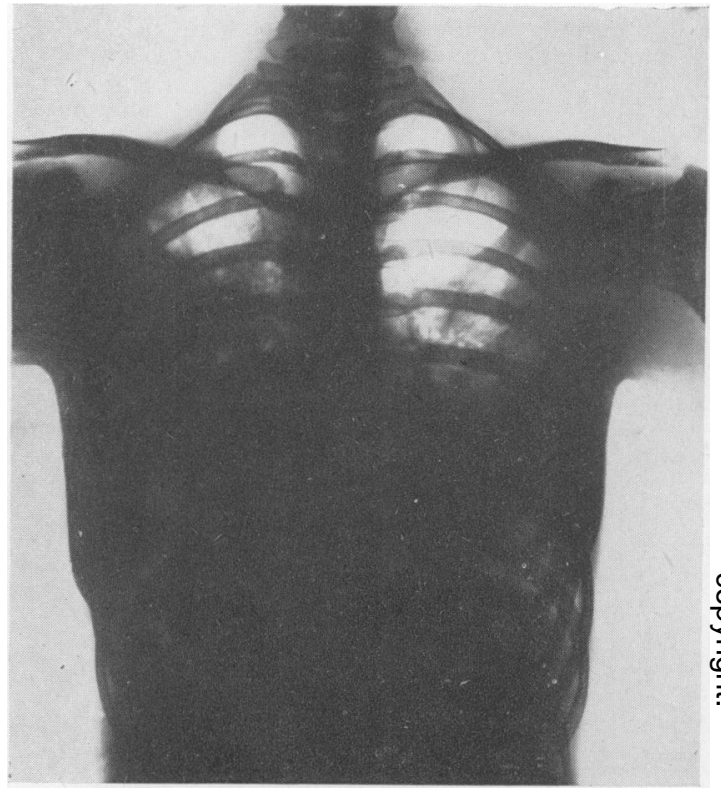

Fig. I.-Case I. Radiological findings on admission. Extensive bilateral consolidation.

6. Rickettsial pneumonia :-
(a) Q. fever.
(b) Typhus.
(c) Rocky Mountain fever.
(d) Spotted fever.
(e) South African tick fever.

Such a classification cannot be all inclusive. The position of each condition in the list gives some indication of the relative importance in this country. The last four rickettsial infections are only included for completeness, while the possible importance of $\mathrm{Q}$. fever will be dealt with at some length.

\section{Influenzal Pneumonia}

Modern knowledge of this condition began with the recovery of influenza A virus from patient's throat washings and the demonstration of neutralizing antibodies against the virus during convalescence by Smith, Andrewes and Laidlaw 


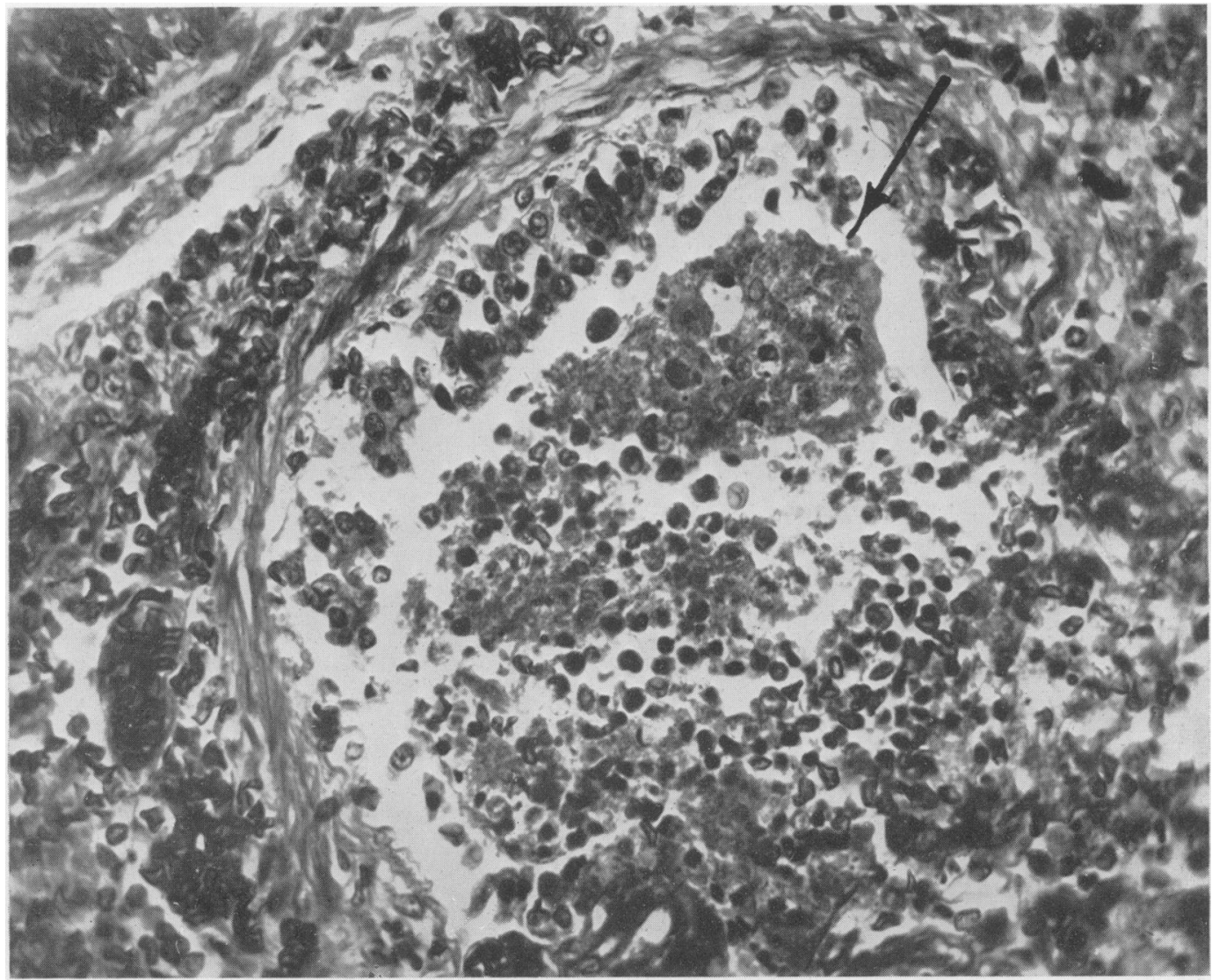

Fig. 2.-Case I. Necrotizing endobronchitis. Arrow shows necrotizing exudate. x 250.

(1933). Further studies have demonstrated another distinct virus, virus $B$, which has similar pathogenic properties. These two viruses are responsible for the major epidemics that occur and it is probable, though not proven, that one was responsible for the pandemic of I918-19. Interepidemic cases occur with some frequency but a number of similar clinical conditions are also met in which specific findings are absent. lt is probable that we are here dealing with separate but closelyrelated viruses. The extreme diversity of symptoms produced by virus $A$ and virus $B$ is well known. The severity of lesions produced may vary from a transient upper respiratory catarrh, associated with a slight fever, to a fulminating septicaemia with heliotrope cyanosis, a condition which may prove fatal within 48 hours of onset. A classical review of the clinical findings, together with pathological changes, was given by Scadding (1937).

Pathological picture. Comparatively little is known of the uncomplicated pathological picture of these virus infections in man. All observers agree that in severe cases likely to be associated with pneumonia, acute tracheobronchitis, extending throughout the whole lung fields, is the initial lesion. In fulminating cases a necrotizing lesion is found, associated with epithelial desquamation of the smaller bronchi; the interstitial tissues show an inflammatory reaction and there is necrosis of the alveolar walls with consequent haemorrhage. Lobar and bronchopneumonic areas are associated, particularly in the severe cases, when pneumococci, staphylococci or haemolytic streptococci abound. Polymorphonuclear leucocytes are abundant at this stage, but are not found earlier. Areas of collapse are frequent, dilatation of bronchi is common, and resolution may be very slow and associated with fibrosis and permanent bronchiectasis.

Clinical picture. The incubation period does not exceed two days. The onset of systemic symptoms is often abrupt, and while in certain localities it may follow a definite pattern; study of a widespread epidemic will reveal much variation. Gastro-intestinal symptoms, nausea, vomiting, 


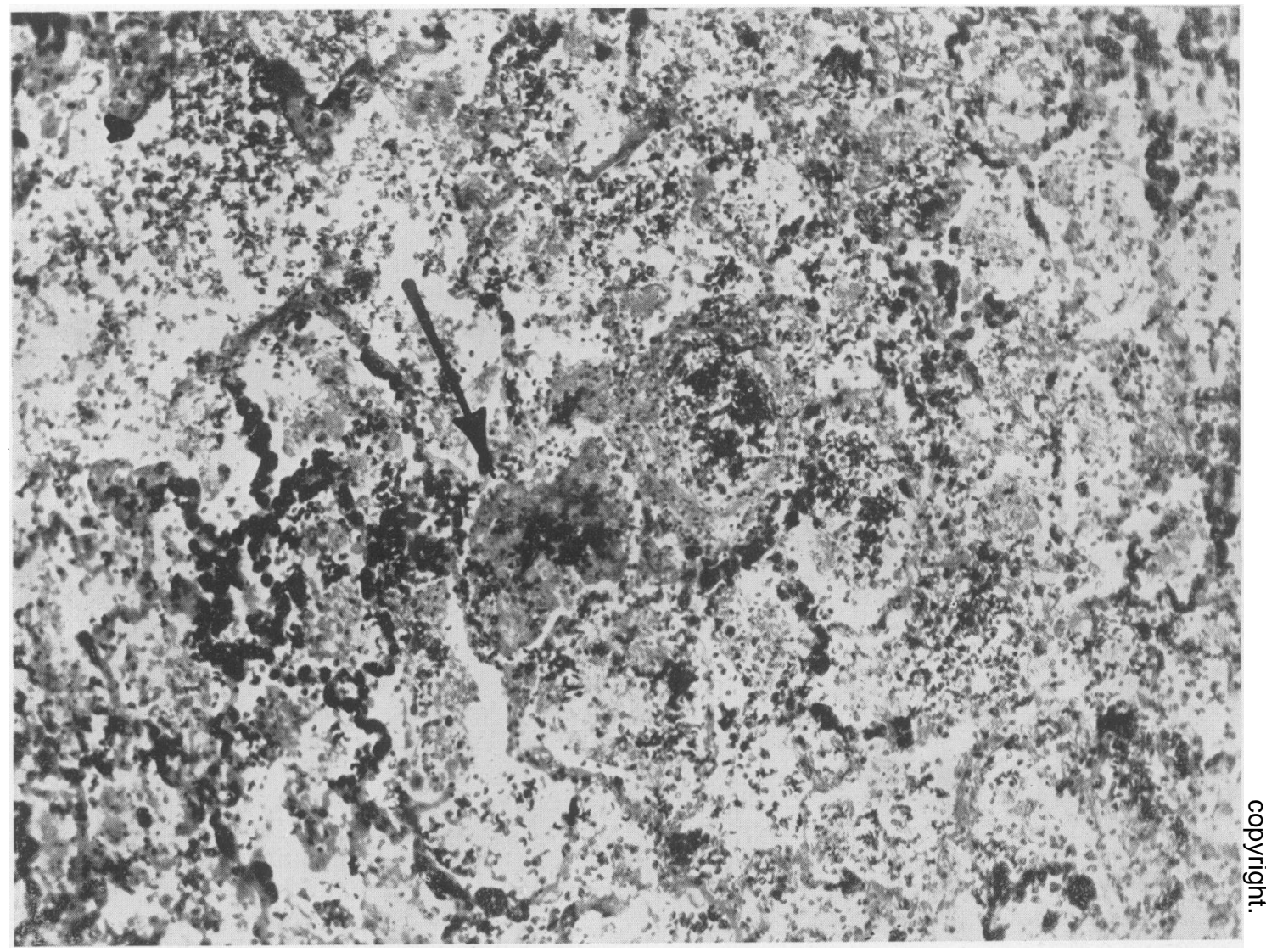

Fig. 3.-Case I. Necrotizing, partly haemorrhagic bronchitis, and bronchopneumonia. Arrow shows necrotizing alveolar exudate. $\mathrm{x} 90$.

diffuse colicky abdominal pain, occasionally associated with diarrhoea, may predominate. At other times ext eme prostration, vertigo and headache may herald the attack. The respiratory symptoms are not so numerous and are easily understood from the outline of the pathology given. Coryzal symptoms are frequent, associated with slight hoarseness. At the outset cough, irritating and non-productive, is usually found, with a substernal soreness amounting to severe pain in the worst cases. A sense of tightness in the chest may progress to a feeling of suffocation. The temperature rises rapidly, reaching $10 I^{\circ}$ to $1 \circ 3^{\circ} \mathrm{F}$. with a corresponding and sometimes excessive rise in pulse rate. In uncomplicated cases the symptoms subside in 48 to 60 hours without the development of physical signs in the lungs other than a few scattered rhonchi. Pneumonic signs often develop some two to three days after the general symptoms have begun to subside. They are seen most frequently in those who have attempted to continue working throughout or who have returned to work too early. They may be manifest by the typical symptoms of lobar pneumonia, but more frequently the previous respiratory troubles return with increasing severity. Temperature gradually rises, associated with an increasing respiration rate and the development of pleural pain. The white blood count, which in the early stages was normal, will now show an increasing leucocytosis. The physical signs will be indicative of areas of collapse mingled with consolidation. Many adventitious sounds may be heard throughout, thus differing from the findings in uncomplicated lobar pneumonia. Risponse to chemotherapy at this stage may be good, but signs of residual lung infection will often be present for many weeks. Even in minor epidemics two or three examples of fulminating septicaemia and bronchopneumonia will be seen when dealing with a population at risk of 200,000 to 300,000 . In these patients the initial pulmonary symptoms are very severe. The acute necrotizing tracheobronchitis permits the easy access of staphylococcus aureus or other organisms to the blood stream and to the finer bronchioles. Most frequently such 
cases are seen in what appear to have been young, healthy adults and despite therapy death ensues within 60 hours, usually less than i 8 hours after admission to hospital.

\section{Case History. Fulminating Pneumonia (Case I)}

D.G. Female. Aged 20. Saleswoman. Previously healthy, noticed sudden onset, two days previously, of cough with small amount of mucopurulent sputum. Rigors followed and pleural pain in right chest, anteriorly, developed rapidly. On admission to hospital she was extremely ill, with severe cyanosis, pulse rate 140 , volume poor and blood pressure unobtainable. Temperature 10 $3^{\circ}$. Respiration 34. Examination of chest showed areas of impaired resonance throughout whole of right lung and left base. There were many 1ales and some patches of tubular breath sounds to be heard in the same situations. White blood count 35,000 . Despite intensive therapy with penicillin, sulphamerazine, oxygen and, finally, eucortone in intravenous drip, the patient steadily deteriorated and died 28 hours after admission. The total duration of symptoms had been 76 hours. Influenza virus $A$ was isolated from throat washings and, later, from lung tissue following autopsy. Staphylococcus aureus was isolated from blood culture and from lung puncture, no sputum being obtainable. X-ray findings confirmed the clinical signs (Case I, Fig. I). The pathological changes in the lungs are well seen in Figs. 2 and 3 (Case 1 ).

Diagnosis. The diagnosis can only be established by recovery and identification of the virus from the respiratory tract and by the rise of significant antibody response. The virus may be obtained from throat washings during the first three days of the disease, by inoculation of chick embryo. It can be identified by agglutination tests with specific anti-sera. An antibody response may be most easily demonstrated by comparing serum estimation on the fifth day with that taken during the second and third week of the disease. The onset of a pneumonic process is judged by increasing severity of the symptoms and signs due to lung disease, a rise in the leucocyte count, which is usually normal in earlier stages, and increasing amounts of semi-purulent sputum. Careful bacteriological assay of the sputum should be done at this stage.

Treatment. In uncomplicated cases, beyond rest in bed, symptomatic treatment only is available. With symptoms suggestive of pneumonia, penicillin intramuscularly (100,000 units fourhourly) should be commenced. This should be continued until 48 hours after temperature has subsided. In severe and fulminant cases an oxygen tent is essential, while penicillin dosage should be
500,000 units four-hourly. As pain and temperature subside breathing exercises should commence. Prolonged convalescence is essential, up to one month being needed by many people. The effect of aureomycin and other newer antibiotics in all types of this condition is unknown.

Preciention. There is increasing evidence that a potent vaccine, used at the outbreak of an epidemic, will give considerable protection for several months against this virus infection, while careful segregation of those infected will do much to lessen the liability to pneumonic complications.

\section{Primary Atypical Pneumonia}

Much discussion still centres around the name of this condition and some physicians doubt if it is a single clinical entity. Scadding (I948) marshals all the arguments against both its nomenclature and its single virus aetiology. However, American physicians of repute who have a wide experience in epidemics, both in the Services and at home, have no doubt as to its clinical existence. Transmission of the disease to human volunteers by viral filtrate adds weight to this view (1946). British observers, too, with wide experience of outbreaks in the Services would support this. In civil practice it is certainly rare to see other than sporadic cases which could fall into this category. Difficulty will remain until virus can be adequately transmitted to and studied in laboratory animals. The work of Eaton (1944), on laboratory passage, still awaits confirmation. The diagnosis is made chiefly by exclusion of all known bacterial and virus infection and has been well summarized by Schoenbach and Bryer (1949).

It is emphasized that the onset is usually gradual with a non-productive cough, often worse at night and which may mimic whooping cough. Pleural pain is uncommon. There is fever, gradually rising in severe cases to $103^{\circ}$, headache, malaise and sometimes substernal pain. Physical examination of the chest reveals little beyond slight impairment of percussion note and scattered adventitious sounds. The $\mathrm{X}$-ray changes are usually more marked than the physical signs and may show extensive areas of consolidation. The white blood count is below 12,000 and often less than 7,500 per $\mathrm{cm}$. The differential count is normal. Pathogenic bacteria are not recoverable from the sputum or upper respiratory tract in uncomplicated cases. Sulphonamides and penicillin in maximum doses do not lead to clinical improvement. Cold haemoagglutinins and agglutinins for non-haemolytic streptococcus M.G. increase gradually during the course of the disease and its convalescence in 40 to 60 per cent. of patients. The blood culture remains sterile throughout.

The incubation period is 7 to 14 days and the 
temperature remains elevated in untreated cases for approximately the same time, but occasional instances have been noted where symptoms and fever continued for seven to ten weeks. The disease is rarely fatal, but a few autopsy findings have been published. These findings are not distinctive and fail to differentiate the condition from other forms of pneumonia, such as those in psittacosis and Q. fever. Patches of widely scattered bronchopneumonia are seen, the bronchi and bronchioles showing desquamation and often being filled with a mucopurulent exudate. There is much interstitial infiltration with mononuclear cells and the alveolar walls are thickened and infiltrated. In many cases the alveoli still contain air.

Discussion continues as to whether there are typical X-ray changes. To the unbiased it seems that there is nothing pathognomonic radiologically and that a wide variation in appearance is seen in different epidemics. Verco (I949) has given an excellent review of the radiological appearances as seen in Australia. In the majority of his cases the radiograms indicated lesions in widely disseminated foci and were somewhat suggestive of miliary tuberculosis. Residual fibrosis and pleural thickening persisted and this finding has been noted by others. A diffuse bronchiectasis may follow this and other virus infection despite doubt cast by Scadding (1948).

Treatment. Difficulty in accurate diagnosis will be very apparent from details given above but it is important to attempt this if only to decide treatment. American observers, notably Meiklejohn and Shragg (1949), have produced convincing evidence that aureomycin brings down temperature and rapidly alleviates symptoms. The patient should be confined to bed until symptoms have subsided and the sedimentation rate has fallen to normal. Distressing cough may need treatment with sedatives such as heroin and codeine. Aureomycin should be started as soon as the diagnosis is reasonably certain. An initial dose of $\mathrm{I} \mathrm{gm}$. by mouth is followed six-hourly by $0.5 \mathrm{gm}$. This should be maintained for a minimum of five days in severe cases but may be discontinued 24 hours after the temperature has returned to normal in those with milder symptoms. The toxicity of this drug is very low, only nausea and occasional vomiting have been noted with any frequency. Breathing exercises should begin early and, as in influenzal cases, convalescence should be sufficiently prolonged to ensure adequate restoration to full health. In civil practice in this country we can recognize an increasing number of patients who are probably suffering from a milder form of this infection and in whom the process does not proceed to pneumonic consolidation if treatment is instituted early. The symptoms are much as outlined, with paroxysmal cough at night being predominant. At first this is non-productive, but may eventually achieve small pellets of muco pus which are slightly bloodstained. Signs in the chest will be indicative of patchy bronchitis and several members of the house may be affected, with symptoms increasing in severity as the small epidemic spreads. Findings at this stage, including radiological ones, will be negative except for rising cold agglutination titres. Immediate alleviation will be obtained from aureomycin, but a limited experience suggests that if treatment is delayed results may be disappointing.

\section{Pneumonia due to Unknown Virus}

As stated previously it is probable that pneumonic processes develop in association with infection from other as yet unidentified viruses. Influenza $A$ and $B$ account for a number of even the minor epidemics, but many similar small outbreaks are seen in which neither virus nor agglutination titres are obtained by present methods. In primary atypical pneumonia, too, the variable 오 findings by laboratory workers, clinicians and particularly by radiologists may be subsequently explained by infection resulting from differing viruses.

\section{Psittacosis or Ornithosis Pneumonia}

Psittacosis is an avian infection with an ex tremely wide host range which is communicable to man. Full investigation of the condition commenced in 1930 when infection was observed in 12 different countries. The source of these cases was South American parrots, but it has been shown since that time that birds ranging from parakeets, pigeons, sparrows and starlings to canaries can be infective sources. Bedson and Bland (1932) demonstrated minute spherical bodies within reticulo-endothelial cells and proved their relationship to infection.

Clinical picture. The incubation period varies from 7 to 14 days. The symptoms commence fairly suddenly and may bear a striking resemblance to those seen in typhoid fever, or more rarely atypical pneumonia. Anorexia, indefinite abdominal pain, slight cough with a dulling of the mental processes, may precede the full-developed picture. The temperature at the outset is $100^{\circ}$ to $101^{\circ}$ : and rises gradually to be maintained at $103^{\circ}$ during the second week. The pulse often remains relatively slow, while the respiration rate may not reflect the extent of lung involvement. Sputum is scanty. Cough may become more troublesome, but pleural pain is infrequent. Anorexia and constipation may be extreme, while apathy and general mental dullness may be associated with incontinence. In severer cases insomnia, disorienta- 
tion, apathy and delirium are found. In untreated and favourable cases the temperature begins to fall in the third week.

The physical signs are mainly confined to the lungs where areas of impaired resonance, associated with persistent rales may be found. Extensive bronchial breathing is rare but radiologically widely scattered areas of irregular consolidation are to be seen. The spleen is palpable in 25 per cent. of cases, while ' rose spots' resembling those seen in typhoid, have been noted in a few cases. Venous thrombosis occurs often as would be expected in patients so immobile. The white cell count is usually normal, but leukopenia is present in 25 per cent. of cases. Temperature subsides gradually and convalescence is prolonged. The lung changes resolve slowly and extensive fibrosis may remain permanently in those areas where the original lesions were severe (Fig. 4). Some outbreaks have carried a mortality of 30 to 40 per cent. Nurses, doctors and laboratory workers have contracted the disease, with some frequency, from contact with patients. It is probable that mild cases are passing undiagnosed, particularly since the host range has widened.

\section{Case History, Psittacosis (Case 2)}

M.W. Female. Aged 29. Admitted on May 14, 1943, with a history of malaise and feverishness for five days, and of rigor two days before. She had no previous chest history and no history of close contact with animals or birds. She appeared very ill, was cyanosed and continued to have rigors for four days. Despite this her respiration rate never rose above 24 per minute, and there was no herpes and no pleural involvement. Wellmarked consolidation of the right upper lobe cleared in a week, but a similar condition gradually developed in the right mid and lower lobes, later associated with consolidation in the left mid zones. She was given $13 \mathrm{~g}$. sulphathiazole and $17 \mathrm{~g}$. sulphapyridine in the first five days, with no improvement. Specific treatment was stopped, and I I days after admission her general condition began to improve. In the first two days she brought up a little sputum which contained normal mouth flora only. Afterwards she had no more sputum. Lung puncture was sterile and blood culture was twice sterile. White cell counts were done every two days and never rose above I 5,000 per $\mathrm{cm}$. of blood with normal distribution of cells. There were no cold agglutinins at any stage. Complement fixation for psittacosis was as follows:Second day, none; fourth day, titre $I: 2$; third week, titre $I: 32$; sixth week, titre $I: 32$. A radiograph of the chest on May 17, 1943, showed consolidation of the lower two-thirds of the right upper lobe (Fig. 5). By May 21, 1943, the right

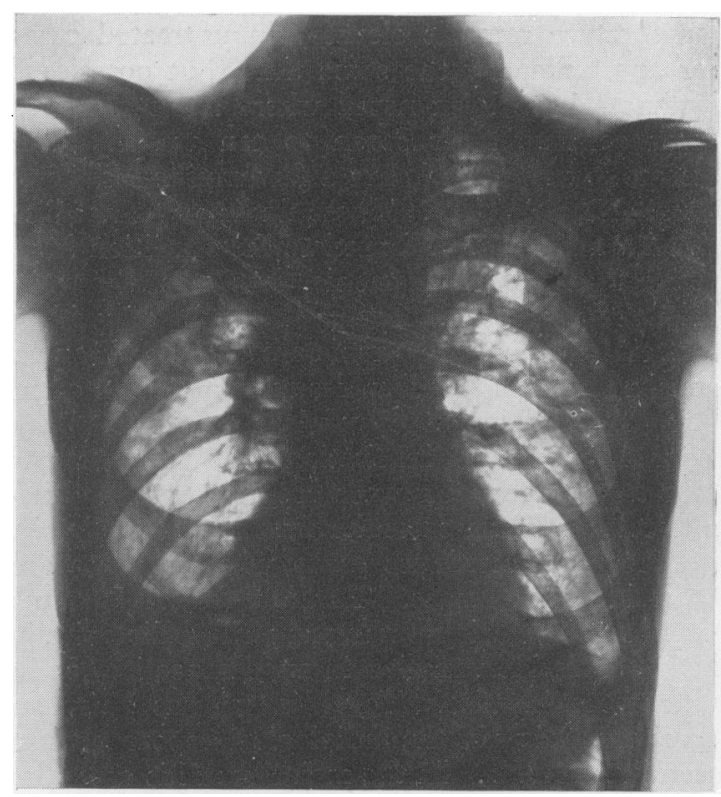

Fig. 4.-Residual fibrosis of right lung two years after severe psittacosis infection.

upper lobe was almost clear, and there was consolidation of the right mid lobe and early con solidation of the left mid zone (Fig. 6). By May 24, I943, consolidation extended to the right base with further consolidation in the left mid zones (Fig. 7). On May 31, 1943, the chest was almost clear, and by July 20, 1943, it was clear.

This patient gave strong serological evidence of infection with a virus of the ornithosis group, and probably represents the clinical picture of the condition uncomplicated by superimposed bacterial infection (owing to early sulphonamide treatment). We have subsequently, within two years, met four other patients clinically and serologically similar (final titres against psittacosis I :32 to $I: 128)$. Failure to isolate a causative agent by animal inoculation is easily attributable to the paucity of material obtained by lung puncture.

Diagnosis. A history of close association with birds should be suggestive, but in those cases seen in this hospital no close contact has been proved. Virus isolation is possible both in the acute and convalescent stages. Inoculation of blood, throat washing, or sputum into mice may yield results in 40 per cent. of cases. Complement fixing antibodies are the most reliable finding on which to base a diagnosis. They may be demonstrated in the blood from the fourth day from the onset of symptoms. A rising titre is important, but in a patient with suggestive symptoms a titre of $I: I 6$ or greater is diagnostic. A higher level may be retained for many months after the infection. Patients with a positive Wassermann may react strongly. 


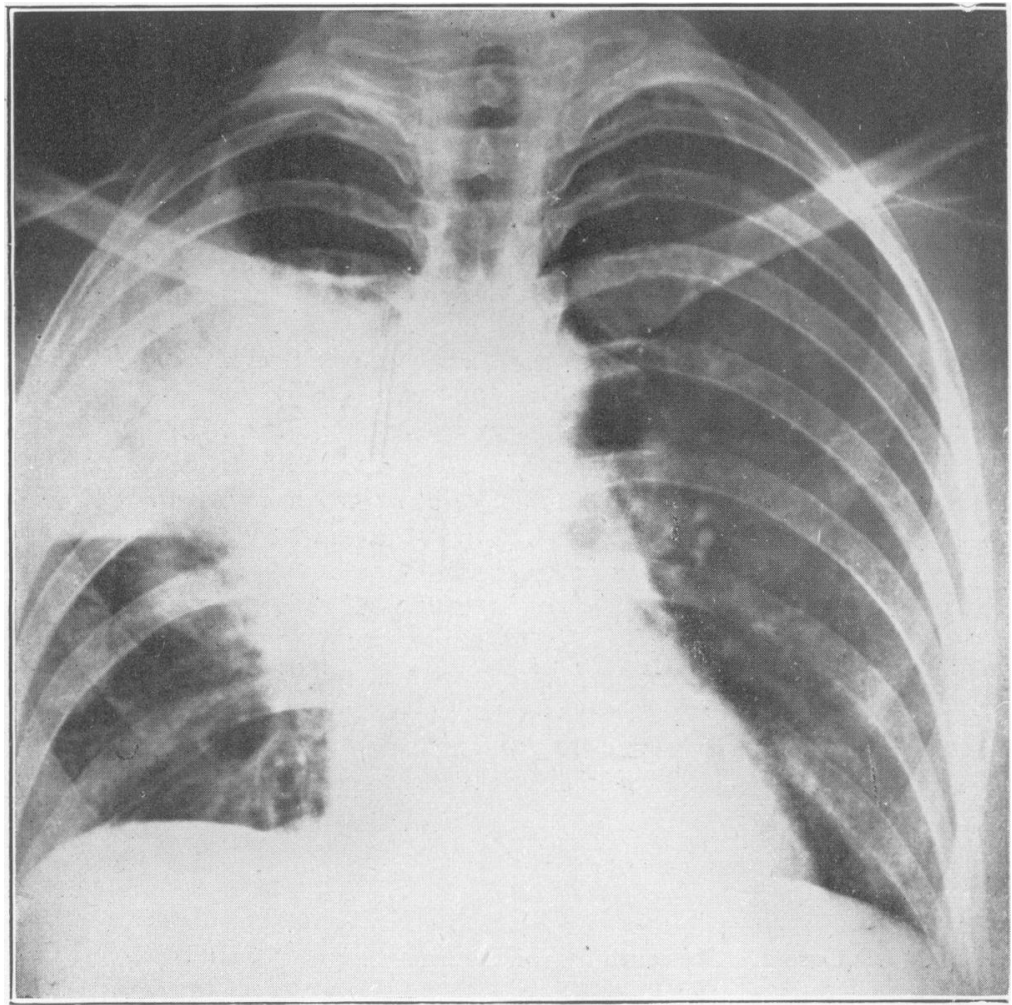

Fig. 5.-Psittacosis. Case 2. Ninth day of the disease.

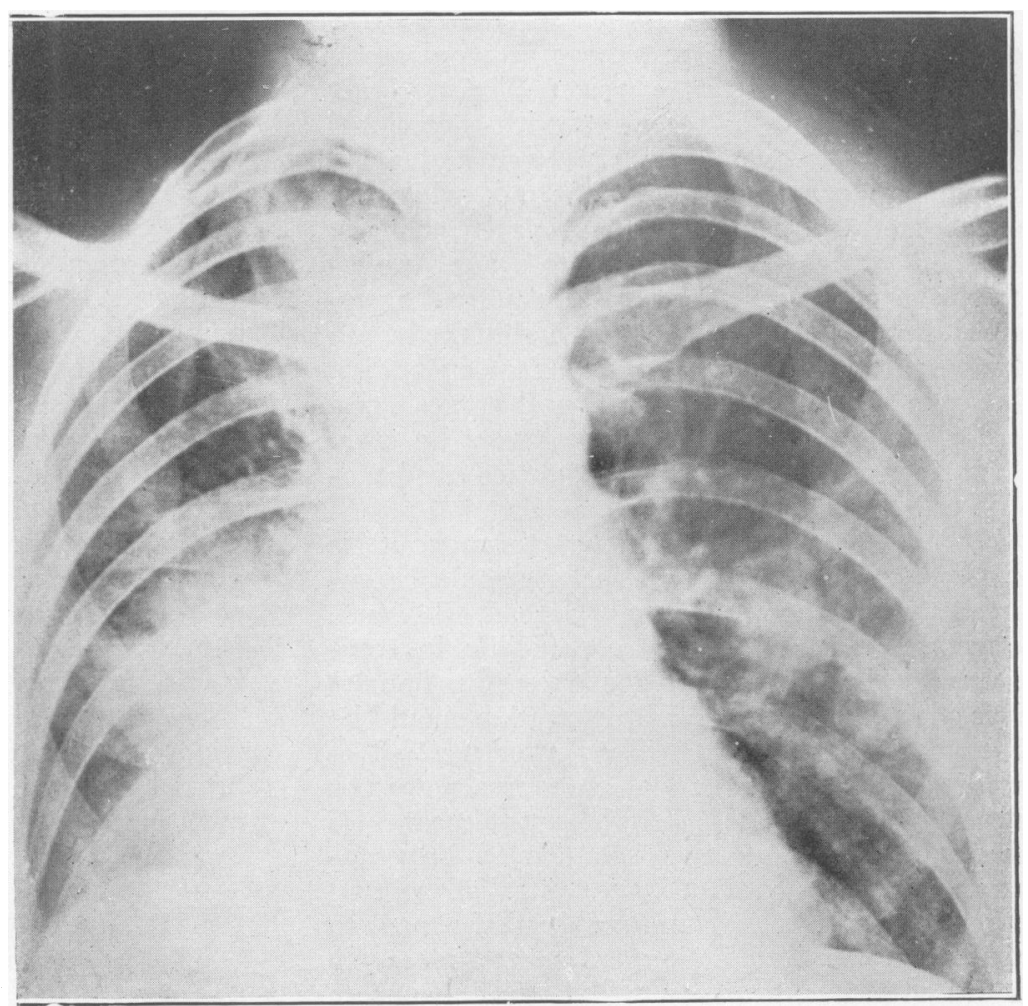

Fig. 6.-Psittacosis Case 2. Thirteenth day of the disease. 


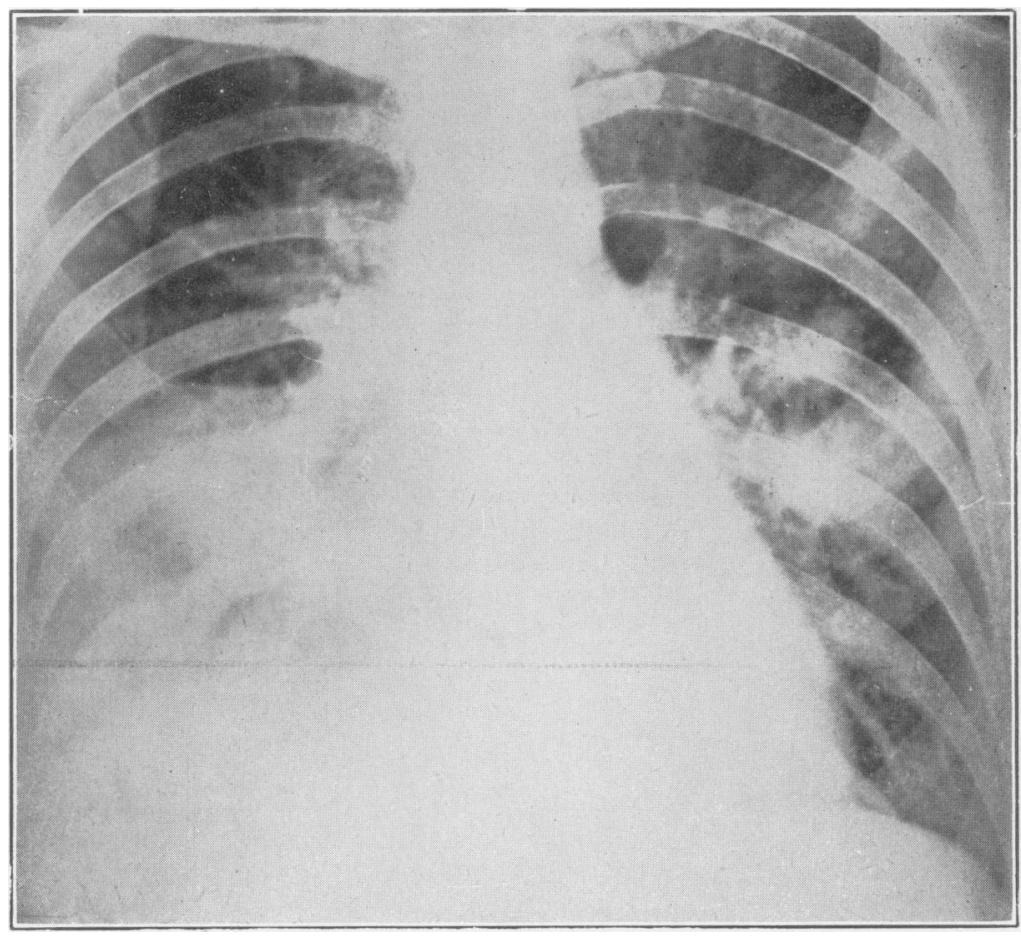

Fig. 7.-Psittacosis Case 2. Sixteenth day of the disease.

Pathology. The lung changes, macroscopically, consist of sharply demarcited, greyish red areas, easily palpable and variable in size. The overlying pleura shows fibrin reaction, with occasional petechiae. Microscopically the large and small bronchi are comparatively unaffected, while the consolidated areas show irregular lobular changes, alveoli filled with fibrin, macrophages and lymphocytes, alternate with comparatively normal structures. Many cells, both in alveoli and in the lymph glands, show the intracellular elementary bodies. The liver shows many areas of focal necrosis and here again the elementary bodies may be seen. The spleen is enlarged by the presence of phagocytic cells.

Treatment. Careful nursing throughout is essential, while very strict isolation should be enforced to limit the possibility of spread. Evidence is accumulating to show that penicillin in comparatively large doses (200,000 units four-hourly) gives good results, but its administration should be continued for at least ten days after the fall of temperature. The effects of aureomycin are not known. Once again prolonged convalescence is essential. Breathing exercises should be commenced early and careful X-ray control of the lung lesions carried out. Every effort should be made to trace the source of infection and control measures should be strict; however, with potential sources so widespread, both detection and prevention may be difficult

\section{Pneumonia Associated with Known Virus Infections}

In measles and severe chicken-pox, lung changes can frequently be demonstrated radiologically. These resemble the diffuse focal lesions which some state to be characteristic of primary atypical pneumonia. They may simulate miliary tuberculosis. At post-mortem disseminated bronchiolitis, peribronchiolitis and bronchopneumonia have been seen in the absence of bacterial infection. A somewhat similar picture is occasionally found in infectious mononucleosis. Again it is only evident in the severer cases (Figs. 8 and 9). Lymphogranuloma venerum can also give the same lung changes, in its extreme form. Lymphocytic choriomeningitis, as its name suggests, usually manifests itself in the central nervous system. However occasionally systemic effects may be widespread and in a few fatal cases changes in the lungs have been encountered which are practically indistinguishable from those of other virus infections.

\section{Rickettsial Pneumonia}

This group does not fall strictly within the classification of virus pneumonia, but the mani- 


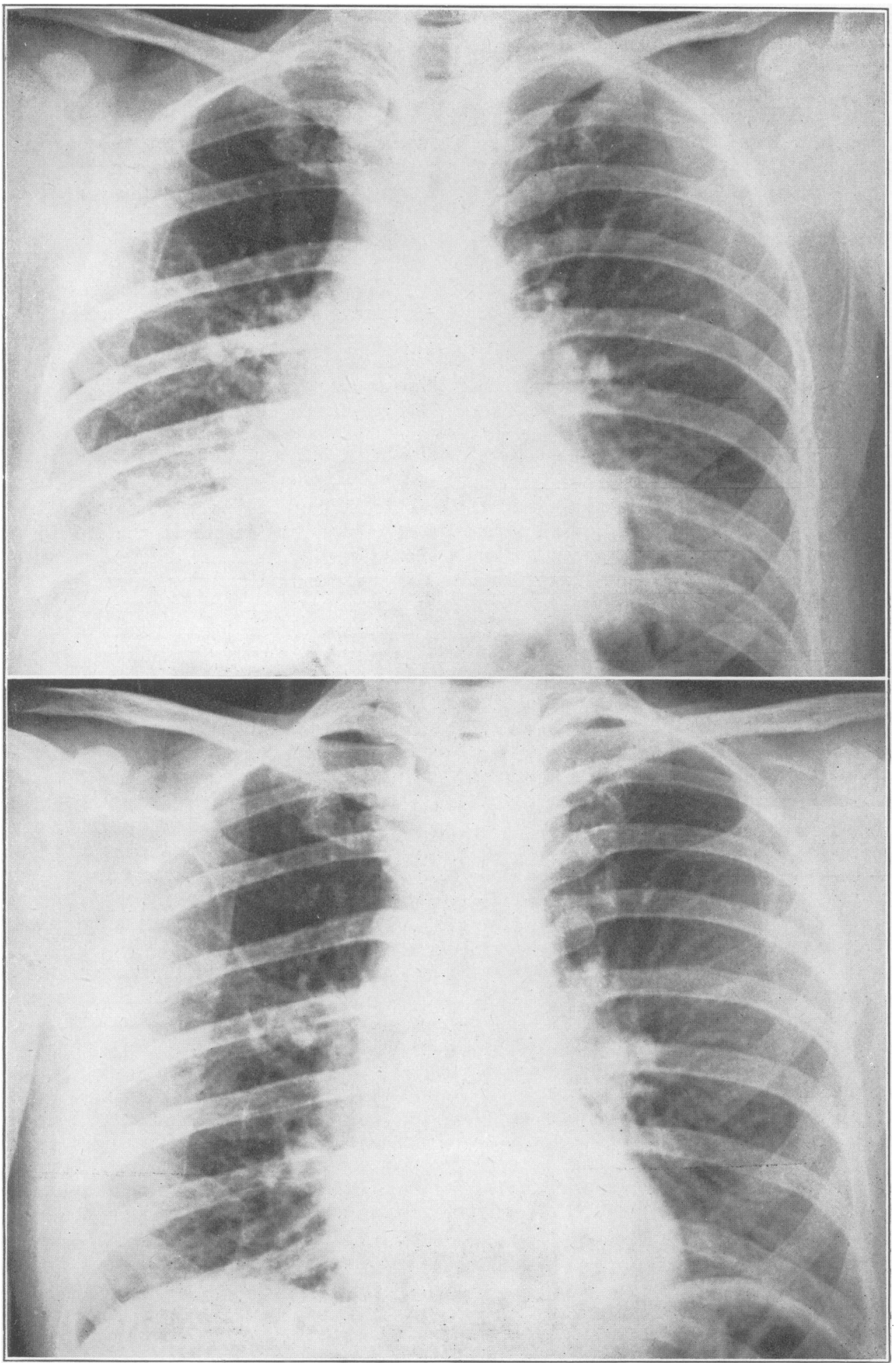

Fig. 8.-Infectious Mononucleosis. Thirteenth day of the disease.

Fig. 9. - Infectious Mononucleosis. Twenty-fifth day of the disease.

Fig. 9

FIG. 8 
festations are so similar and the causal agents so akin to virus that it seems desirable to discuss it.

\section{Q. Fever}

Recent cases of Q. fever in England are reported by Harman (1949) and Manderson (1949), and brilliant pathological investigations by Stoker, et al. (1949), leave no doubt that this condition may soon assume serious clinical importance here. It was first recognized as a human disease in Queensland, Australia, in 1935, and the causal agent, known as rickettsia burneti was identified by Burnett and Freeman (1937).

Clinical features. The incubation period varies from 12 to 40 days, and is usually between two and three weeks. As far as is known there is universal susceptibility but one attack confers immunity for an unknown duration. The important symptoms of the disease are fairly constant. The onset is sudden, although often mild, the temperature rising to $102^{\circ}$. Two days later it often reaches $104^{\circ}$, to return to normal several times during the day. These temperature variations are accompanied by drenching sweats and sometimes by rigors. It may persist for six to ten days. The pulse rate is often proportionately slow. Headache is often severe, commonly frontal, and associated with pain on moving the eyes, and there is a varying degree of photophobia. Loss of appetite is often extreme, accompanied by nausea. Cough is not notable until the fifth day, when pleural pain may be present. Sputum is scanty and occasionally blood stained after a severe paroxysm of coughing.

Physical signs in the chest may be scanty throughout and an assessment of the lung condition can only be made on the radiological findings. These may be variable and quite indistinguishable from those found in atypical pneumonia. No typical cutaneous lesions are seen but a faint macular rash may be present in ro per cent. of cases. The spleen, although somewhat enlarged, is not usually palpable. Lassitude, general weakness and indefinite pains in limbs and back may continue for many weeks. The mortality is low, being variously reported as between $I$ and 5 per cent.

The diagnosis, when suspected, can be confirmed by agglutination reaction. A specific titre of $\mathrm{I}: 20$ or over is regarded as diagnostic. A very significant rise often takes place during the second and third week of convalescence, which may persist for many months if not years. The findings at autopsy do not differ materially from those described in psittacosis.

Treatment. Aureomycin and chloromycetin are probably effective antibodies in this condition, but present evidence is not conclusive. Mild cases are often of short duration and do not justify the use of these drugs until the supply position is easier than at present.

The host range is wide and we have insufficient evidence yet to suggest how clinical cases may arise in this country. Milk, however, can be said to be one possible cause, while although spread from person to person is doubted, infected faeces and certainly organs at autopsy can transmit the disease.

Typhus, Rocky Mountain Fever, Spotted Fever, South African Tick Fever

It is improbable that these conditions will be of clinical importance in the British Isles, and consequently no fuller description will be given. It is worth remembering, however, that the lung changes may be a very important aspect in some of the cases. Here, too, evidence of the benefit of aureomycin in treatment is accumulating.

\section{Conclusions}

I. In $I_{5}$ to 20 per cent. of patients admitted to hospital with pneumonia, we fail to find a convincing bacterial agent.

2. Virus infection explains an appreciable percentage. Complete viral diagnosis demands a very careful history, full assessment of physical signs and radiological evidence, together with very timeconsuming laboratory assay.

3. Specific virus diseases are gradually heing separated.

4. Aureomycin and the newer antibiotics are likely to yield increasing benefit in treatment.

5. The emerging importance of $Q$. fever in this country is emphasized.

\section{Acknowledgments}

I am indebted to the editor of Thorax for permission to use the plates in Figs. 5 to 9. I have received considerable assistance from many mem- $\sigma$ bers of the staff at Central Middlesex Hospital, N whom I thank.

\section{BIBLIOGRAPHY}

BEDSON, S. P., BLAND. J. O. W.(1932), Brit. F. Exp. Path., 13,461. BURNET, F. M., FREEMAN, M. (1937), Med. Ұ. Aust., $2,209$. COMMISSION ON ACU'TE RESPIRATORY DISEÁSES (1946), Bull. Fohns Hopkins Hosp. 79, 97-167.

EATON, M. D., MEIKLEJOHN, G., and VAN HERRICK, W. (1944), $\mathfrak{F}$. Exp. Med., 79, 649, 688 .

HARMAN, J. B. (1949), Lancet, ii, 1028.

MANDERSÖN, W. G.'(1949), Ibid., ii, 1085. MEIKLEJOHN, G., SHRAGG, R. I. (1949), f. Amer. Med. Ass., 740, 39I.

REIMANN, H. A. (1946), F. Amer. Med. Ass., 133, 487.

SCADDING, J. G. (1937), Quart. Ұ. Med., 6, 425.

SCADDING, J. G. (1948), Lancet, i, 89.

SCHOENBACH, E. B., BRYER, M. S. (1949), f. Amer. Med. Ass., 139, 275 .
SMITH, W., ANDREWES, C. H., and LAIDLAW, P. P. (1933), SMITH, W. AND

STOKER, M. G. G. P., MACCALLUM, F. O., and MARMION B. P.'(1949). Jbid., ii, 1026.

VERCO, P. W. ' ' 949), Thorax, 4, 152. 